\title{
A Resiliência como Instrumento de Análise da Gestão Municipal de Riscos e Desastres
}

\author{
Carlos Mello Garcias \\ Pontifícia Universidade Católica do Paraná - Curitiba - Paraná - Brasil \\ Larissa Maria da Silva Ferentz \\ Pontifícia Universidade Católica do Paraná - Curitiba - Paraná - Brasil \\ Eduardo Gomes Pinheiro \\ Pontifícia Universidade Católica do Paraná - Curitiba - Paraná - Brasil
}

\begin{abstract}
Resumo
A problemática dos impactos negativos resultantes da ocorrência de eventos extremos nas cidades tem apresentado cada vez mais a necessidade da implantação de medidas que auxiliem os gestores na minimização das vulnerabilidades de seus municípios. Para isto, a gestão de riscos de desastres (GRD) é essencial e deve ser exercida nas diferentes áreas setoriais, a fim de adaptar os processos nas suas cinco etapas principais: prevenção, mitigação, preparação, resposta e recuperação. Tendo em vista isto, o objetivo principal desta pesquisa foi analisar a gestão municipal de proteção e defesa civil de União da Vitória, sendo este, o município que apresenta o maior número de ocorrências de inundação do estado do Paraná. A metodologia utilizada se baseia na aplicação de dois indicadores: Scorecard Detalhado de Resiliência a Desastres, da ONU e Indicador de Preparação a Desastres para Cidades (IPDC) da PUCPR e CEPED/PR. Ao todo, foram avaliados 164 itens, resultando em $52,5 \%$ de resiliência no enfrentamento de desastres de inundação em União da Vitória. Dentre as análises qualitativas, foi possível observar o perfil da gestão atual do município, apresentando como aspectos a forte cultura de convivência com as enchentes; a construção de novas residências nas proximidades do rio; e a falta de capacitação dos moradores, mesmo com a grande frequência de cheias. Por fim, foi possível concluir que a utilização de instrumentos que avaliem a gestão de riscos e desastres dos municípios é essencial para a promoção de medidas que auxiliem os gestores a tornarem suas cidades mais resilientes.
\end{abstract}

Palavras-chave: Gestão de Riscos e Desastres. Gestão Municipal. Resiliência. Indicador. Inundação.

\section{Resilience as an Instrument of Analysis of Municipal Risk and Disaster Management}

\section{Abstract}

The problem of the negative impacts resulting from the occurrence of extreme events in cities has increasingly presented the need for the implementation of measures that assist managers in minimizing the vulnerabilities of their municipalities. To this end, disaster risk 
management (DRM) is essential and should be pursued in the different sectoral areas in order to adapt processes in their five main steps: prevention, mitigation, preparedness, response and recovery. In view of this, the main objective of this research was to analyze the municipal management of protection and civil defense of União da Vitória, being this, the municipality that presents the highest number of flood occurrences in the state of Paraná. The methodology used is based on the application of two indicators: Detailed UN Disaster Resilience Scorecard and Disaster Preparedness Indicator for Cities (IPDC) of PUCPR and CEPED/PR. Altogether, 164 items were evaluated, resulting in $52.5 \%$ resilience in the face of flood disasters in União da Vitória. Among the qualitative analyzes, it was possible to observe the profile of the current management of the municipality, presenting as aspects the strong culture of coexistence with the floods; the construction of new residences near the river; and the lack of capacity of the residents, even with the high frequency of floods. Finally, it was possible to conclude that the use of instruments that assess municipal risk and disaster management is essential for the promotion of measures that help managers to make their cities more resilient.

Keywords: Risk and Disaster Management. Municipal Management. Resilience. Indicator. Inundation.

\section{La Resiliencia como Instrumento de Análisis del Riesgo Municipal y la Gestión de Desastres}

\section{Resumen}

La problemática de los impactos negativos resultantes de la ocurrencia de eventos extremos en las ciudades ha presentado cada vez más la necesidad de la implantación de medidas que auxilien a los gestores en la minimización de las vulnerabilidades de sus municipios. Para ello, la gestión de riesgos de desastres (GRD) es esencial y debe ser ejercida en las diferentes áreas sectoriales, a fin de adaptar los procesos en sus cinco etapas principales: prevención, mitigación, preparación, respuesta y recuperación. En este sentido, el objetivo principal de esta investigación fue analizar la gestión municipal de protección y defensa civil de Unión de la Victoria, siendo éste, el municipio que presenta el mayor número de ocurrencias de inundación del estado de Paraná. La metodología utilizada se basa en la aplicación de dos indicadores: Scorecard Detalle de Resiliencia a Desastres, de la ONU e Indicador de Preparación a Desastres para Ciudades (IPDC) de la PUCPR y CEPED/PR. En total, se evaluaron 164 ítems, resultando en el 52,5\% de resiliencia en el enfrentamiento de desastres de inundación en Unión de la Victoria. Entre los análisis cualitativos, fue posible observar el perfil de la gestión actual del municipio, presentando como aspectos la fuerte cultura de convivencia con las inundaciones; la construcción de nuevas residencias en las proximidades del río; y la falta de capacitación de los residentes, incluso con la gran frecuencia de inundaciones. Por último, es posible concluir que la utilización de instrumentos que evalúen la gestión de riesgos y desastres de los municipios es esencial para la promoción de medidas que ayuden a los gestores a hacer sus ciudades más resilientes.

Palabras clave: Gestión de Riesgos y Desastres. Gestión Municipal. La resiliencia. Indicador. Inundación. 


\section{Introdução}

O processo de urbanização das cidades tem aumentado o número de pessoas que vivem em situação de vulnerabilidade. Tanto a baixa oferta de empregos quanto a prospecção imobiliária desigual têm resultado na ocupação de áreas irregulares e de assentamentos precários urbanos, trazendo como consequência moradias localizadas em áreas suscetíveis a riscos de desastres (MORENO, OYEYINKA e MBOUP, 2010).

Esta relação, entre riscos e situações de desigualdade social, tem sido apresentada desde 1987 com o relatório Brundtland, onde já se discutia sobre as pressões diretas no meio ambiente como resultado de populações que não possuem seus direitos básicos de infraestrutura e moradia, assim como os efeitos sofridos por estas comunidades na ocorrência de eventos extremos (BRUNDTLAND et al., 1987). Este tipo de problema continua ocorrendo devido às decisões errôneas tomadas no passado, sendo necessária uma mudança cultural e estratégica que vise a redução dos riscos das ameaças naturais ou humanas nas cidades (POTT e ESTRELA, 2017).

Devido a frequência destes eventos extremos, do número de pessoas atingidas por eles e das grandes perdas econômicas sofridas pelos municípios, que a resiliência tem se tornado uma necessidade mundial. "As ameaças naturais deveriam constituir-se na principal preocupação de gestores públicos, pois os impactos desses eventos são cada vez mais caros" (ONU, 2010, p. 3). Incorporar a resiliência nos processos de gestão, levando em conta a redução dos riscos de desastres, auxilia o desenvolvimento de ações e estratégias que visem a minimização dos impactos negativos provenientes das catástrofes (CHRISTENSEN, LEWIS e ARMESTO, 2016).

Por isto a gestão municipal é fundamental neste processo, já que os representantes locais são os interlocutores entre a população e os setores governamentais. A constituição de novas metas, que considerem não apenas medidas para a resposta durante os desastres, mas que também permitam o planejamento prévio para prevenção de riscos e reconstrução das cidades, é de extrema importância e deve ser exercido tanto pelas áreas setoriais quanto pela participação de toda a sociedade civil (ONU, 2010).

Deste modo, a integração da Gestão de Riscos de Desastres (GRD) nos processos organizacionais e de decisão dos municípios é essencial para a implantação de práticas que visem a prevenção de impactos negativos resultantes destes eventos (UNISDR e CEPED PR, 2010). Além disto, a preparação e a mitigação de riscos de desastres "são os pontos chave para orientar um bom planejamento urbano, desenvolvimento social e administração cotidiana das cidades” (ONU, 2010, p.22).

\section{Gestão de Riscos e Desastres}

A gestão de riscos e desastres (GRD) é formada por cinco etapas principais, sendo a prevenção, mitigação e preparação pertencentes à gestão de riscos, e a resposta e reconstrução pertencentes à gestão de desastres (CEPED UFSC, 2012) (Figura 1).

\section{Figura 1. Gestão de Riscos de Desastres}




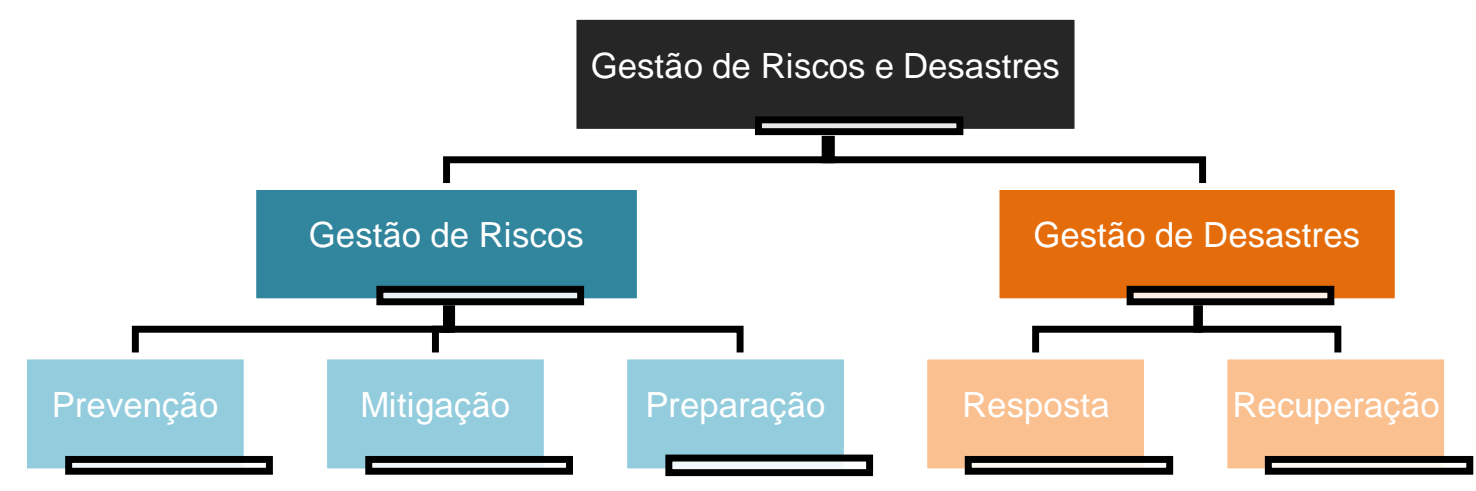

Fonte: elaboração própria.

Nas etapas da gestão de riscos, a prevenção se baseia na identificação de riscos e nos meios necessários para reduzir ou impedir que ocorram. Isso é feito por meio de políticas públicas, legislação, organizações e conscientização da população, promovendo uma cultura de prevenção; a mitigação é o estágio de reduzir os efeitos negativos encontrados em termos de ameaças de degradação natural, tecnológica e ambiental. Isso é feito através de estratégias e do desempenho da Defesa Civil; e a preparação consiste em atividades e medidas que devem ser tomadas para fornecer meios para que indivíduos e organizações reduzam perdas e danos durante os eventos (EIRD/ONU, 2004; PINHEIRO, 2017).

Já na gestão de desastres, a resposta se baseia nas direções, mobilizações e ações estratégicas que devem ser realizadas rapidamente, a fim de interceptar e reduzir os danos que os desastres podem causar, principalmente em relação às perdas humanas; enquanto que a recuperação consiste nas decisões e ações tomadas após o desastre, para melhorar e restaurar as condições da comunidade afetada. Esta etapa é também uma oportunidade para novas medidas para reduzir o risco de desastres locais (EIRD/ONU, 2004; PINHEIRO, 2017).

A implantação da gestão de riscos e desastres no Brasil é instituída pela Lei Federal 12.608 de 2012, Política Nacional de Proteção e Defesa Civil (PNPDEC), pelo Sistema Nacional de Proteção e Defesa Civil (SINPDEC) e pelo Conselho Nacional de Proteção e Defesa Civil (CONPDEC). Tavanti e Spink (2014, p. 3) acreditam que este sistema "é uma proposta inovadora em relação às legislações anteriores, pois, ao incorporar uma concepção de redução de riscos de desastres, avança em vários aspectos", principalmente quanto as articulações da União, Distrito Federal, estados e municípios.

No Estado do Paraná, a Coordenadoria Estadual de Defesa Civil foi criada pelo Decreto 3.002 de 1972, passando ao âmbito da Casa Militar pela Lei 9.943 de 1992. Atualmente, o Sistema Estadual de Proteção e Defesa Civil (SEPDEC) é regulamentado pelo Decreto Estadual 9.557 de 2013, sendo formado por órgãos, setores e instituições com papéis essenciais na redução dos riscos de desastres (PINHEIRO, 2017) (Figura 2). 
Figura 2. Estrutura Organizacional

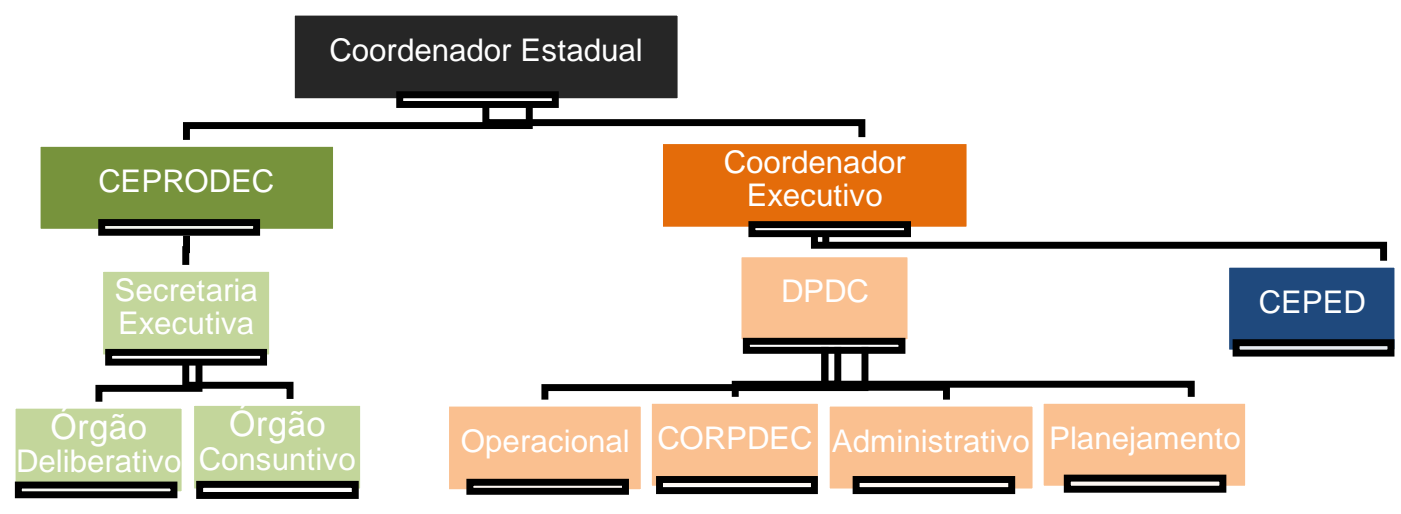

Fonte: elaboração própria.

Todo este processo se resume no apoio aos municípios que apresentam situação de emergência ou estado de calamidade pública durante ou após os desastres, assim como na promoção do desenvolvimento de capacidades previamente aos eventos. Como não existe uma fórmula padrão para que estes eventos extremos não aconteçam, é importante que os gestores e a população recebam esta capacitação, a fim de preparar as comunidades para o enfrentamento dos riscos e das ameaças. Por isto que a execução de medidas estruturais e não estruturais são necessárias, tanto na forma organizacional, quanto na administrativa e na operacional (UNISDR, 2004; VESTENA, 2007).

Para auxiliar os gestores quanto a efetividade deste processo, tem-se a inclusão da resiliência na gestão de riscos e desastres, consolidando as chances do município em alcançar um desenvolvimento contínuo e mais sustentável. Isto é possível porque a resiliência tem o objetivo de alcançar e integrar todos os setores governamentais e sociais, de tal modo que não só os sistemas sejam reslientes, mas que as pessoas também se tornem, resultando assim em uma maior preparação, organização, adaptação e reconstrução na ocorrência de desastres (FOLKE et al., 2002).

\section{Resiliência na Gestão de Riscos de Desastres}

A resiliência pode ser definida como a "capacidade de indivíduos, comunidades, instituições, empresas e sistemas dentro de uma cidade para sobreviver, se adaptar e crescer [...] rapidamente perante o impacto de qualquer tamanho ou crise e manter a continuidade dos seus serviços" (CHRISTENSEN, LEWIS e ARMESTO, 2016, p. 32). Ou seja, gestores e comunidades resilientes se recuperam mais rápido dos imapctos resultantes de eventos extremos, fazendo com que as atividades cotidianas das cidades voltem ao normal pouco tempo após a ocorrência de desastres.

Para que isto ocorra, primeiramente será necessária uma mudança na visão dos gestores, de tal forma que as preocupações não sejam apenas relacionadas às ações de resposta e recuperação, onde se avaliam principalmente os prejuízos econômicos e danos materiais, mas que também visem os impactos humanos de pessoas que 
convivem com o risco diariamente (FREITAS, et. al., 2014; SULAIMAN E ALEDO, 2016). Por meio da gestão de riscos é possível diminuir as vulnerabilidades e aumentar a capacidade de antecipação e resposta quanto à ocorrência de catástrofes (PNRRC, 2017).

Destaca-se que tanto a falta de preparação municipal, quanto a ineficiência de ações de prevenção e de recuperação resultam em prejuízos para os diversos setores das cidades (BAUMEL et al, 2013). Deste modo, quando os desastres ocorrem é importante que se tenha um processo de prevenção e preparação bem estruturados, a fim de se evitar a destruição de infraestruturas, a interrupção de serviços básicos, danos e prejuízos econômicos, assim como evitar perdas e danos humanos (ONU, 2012).

"A necessidade de explicar a resiliência em um mundo de transformações é uma perspectiva que deve tornar-se incorporada em estratégias e política" (FOLKE et al., 2002, p. 440). Por isto a gestão municipal é essencial neste processo, pois "sua participação e engajamento representa um aspecto vital na construção de cidades resilientes" (UNISDR e CEPED PR, 2010, p. 9), já que os representantes locais são os primeiros a realizar as antecipações, o gerenciamento e a redução dos riscos de desastres durante todo o processo (ONU, 2010; ONU, 2012). A utilização de indicadores como instrumentos de auxílio da gestão é muito importante, pois eles podem permitir o monitoramento de ameaças para emissão de alertas quanto a fatores que possam prejudicar a resiliência. Desta forma a política deve estimular as pessoas quanto sua capacidade de adaptação aos riscos, investindo em aprimoramentos tecnológicos e treinamentos de pessoas (FOLKE et al., 2002).

Levando em conta que "a governança urbana tem um papel crucial no aumento da resiliência, na mitigação das mudanças climáticas, na eficiência do uso dos recursos e, assim sendo, em assegurar a sustentabilidade" (ONU, 2015b, p.9), a busca por cidades mais resilientes deve partir dos governos locais, de modo que os gestores auxiliem as comunidades a estarem aptas quanto ao enfrentamento de desastres, assim como na rápida recuperação após os eventos (ONU, 2010).

Estes fatores representam a necessidade do compromisso que os governos devem ter com as cidades, a fim de se permitir a efetividade no processo de tomada de decisões quanto a redução e prevenção de danos materiais e humanos em caso de desastres. Isto pode ser realizado por meio de desenvolvimento sustentável integrado e da capacitação de pessoas mais resilientes (ONU, 2010). Desta forma, é importante que se adotem estratégias para o alcance da resiliência, assim como meios de comunicação que preparem os gestores e as populações quanto ao real entendimento do gerenciamento de riscos de desastres, a fim de transformar os municípios em lugares mais seguros, resilientes e sustentáveis (ONU, 2015a).

Por consequência disto, outro ponto importante para que uma cidade construa a resiliência é a integração, não apenas do governo e de instituições públicas e privadas, mas também de cada cidadão. As pessoas devem aprender a confiar e ajudar sua comunidade para que a vizinhança se torne mais forte e apta para agir em casos de necessidade (ALDRICH, 2017). Isto ressalta que a gestão de riscos de desastres não é apenas de responsabilidade da Proteção e Defesa Civil, mas de todos que formam os municípios, sejam as universidades, a comunidade, os funcionários públicos ou do setor privado (UNISDR e CEPED PR, 2010). 
Sendo assim, os investimentos e intervenções que estão sendo realizadas nas cidades pela busca da resiliência são uma oportunidade para repensar a forma como se está lidando com a gestão de riscos de desastres, principalmente por ela se tratar de um sistema de capacitação unilateral quanto à resistência de impactos que visam o alcance do desenvolvimento sustentável (ONU, 2015a).

\section{Metodologia}

A análise da resiliência na gestão de riscos e desastres pode ser avaliada por meio da aplicação de dois instrumentos principais: o Disaster Resilient Scorecard for Cities do Escritório das Nações Unidas para a Redução do Risco de Desastres (UNISDR) e o Indicador de Preparação a Desastres para Cidades (IPDC) da Pontifícia Universidade Católica do Paraná (PUCPR) e do Centro Universitário de Estudos e Pesquisas sobre Desastres (CEPED/PR).

O Disaster Resilient Scorecard for Cities é um instrumento desenvolvido pelo UNISDR, sendo uma ferramenta utilizada pelos governos locais para monitoramento e análise da sua própria atuação perante a ocorrência de ameaças de origem natural ou tecnológica. A estrutura do presente indicador foi desenvolvida a partir dos dez passos para a construção de cidades resilientes, assim como em atendimento ao Marcos Globais para a redução de riscos de desastres (UNISDR, 2017).

Sua primeira versão foi desenvolvida e apresentada na Conferência Mundial de Hyogo (2005-2015). Atualmente o Scorecard foi atualizado, visando o atendimento do Marco de Sendai (2015-2030). Ele é formado a partir de dez dimensões (Tabela 1), sendo estas subdivididas em 118 indicadores de âmbito institucional, ambiental e urbano. Este instrumento visa o desenvolvimento local por meio de estratégias de redução de riscos de desastres, sendo um bom avaliador da atuação dos gestores municipais em curto e longo prazo. As análises consideram os impactos negativos de eventos extremos perante as infraestruturas, o meio ambiente e a sociedade (UNISDR, 2017).

Destaca-se que as dimensões podem ser subdivididas em três grandes grupos principais, onde as de número 1 a 3 se referem à governança e à capacidade financeira, as de 4 a 8 consideram o planejamento e preparação de desastres, e as de 9 a 10 correspondem à resposta e recuperação pós-desastre. Com esta estrutura, 0 Scorecard permite que os gestores locais entendam os riscos de seus municípios, assim como conheçam sua capacidade de mitigação e resposta frente aos desastres (UNISDR, 2017). 
Tabela 1. Dimensões do Scorecard

\begin{tabular}{|c|c|}
\hline Dimensões do Scorecard & Descrição \\
\hline 1. Organizar a resiliência de desastres & $\begin{array}{l}\text { Adotar uma estrutura organizacional e identificar os } \\
\text { processos necessários para compreender e agir na } \\
\text { redução dos riscos de desastres. }\end{array}$ \\
\hline $\begin{array}{l}\text { 2. Identificar, compreender e usar } \\
\text { cenários de riscos atuais e futuros }\end{array}$ & $\begin{array}{l}\text { Os governos locais devem identificar e compreender seus } \\
\text { cenários de risco e usar esse conhecimento como uma } \\
\text { importante informação para a tomada de decisões. }\end{array}$ \\
\hline $\begin{array}{l}\text { 3. Fortalecer a capacidade financeira } \\
\text { para resiliência }\end{array}$ & $\begin{array}{l}\text { Compreender o impacto econômico das catástrofes e a } \\
\text { necessidade de investimento em resiliência. Identificar e } \\
\text { desenvolver recursos financeiros mecanismos que podem } \\
\text { suportar atividades de resiliência. }\end{array}$ \\
\hline $\begin{array}{l}\text { 4. Buscar pelo desenvolvimento } \\
\text { urbano resiliente }\end{array}$ & $\begin{array}{l}\text { O ambiente construído precisa ser avaliado e tornado } \\
\text { resiliente, conforme aplicável. }\end{array}$ \\
\hline $\begin{array}{l}\text { 5. Proteger os sistemas naturais para } \\
\text { melhorar as funções de proteção } \\
\text { oferecidas pelos ecossistemas }\end{array}$ & $\begin{array}{l}\text { Proteger os sistemas naturais para melhorar as funções de } \\
\text { proteção oferecidas pelos ecossistemas. Identificar, } \\
\text { proteger e monitorar os serviços ecossistêmicos que } \\
\text { conferem um benefício de resiliência ao desastre. }\end{array}$ \\
\hline $\begin{array}{l}\text { 6. Fortalecer a capacidade } \\
\text { institucional para resiliência }\end{array}$ & $\begin{array}{c}\text { É importante garantir que todas as instituições tenham as } \\
\text { capacidades necessárias para desempenhar seus papéis } \\
\text { para a resiliência de uma cidade. }\end{array}$ \\
\hline $\begin{array}{l}\text { 7. Encontrar e fortalecer a } \\
\text { capacidade social para resiliência }\end{array}$ & $\begin{array}{l}\text { Garantir a compreensão e o fortalecimento da capacidade } \\
\text { societária de resiliência. Cultivar um ambiente de conexão } \\
\text { social que promova uma cultura de ajuda mútua por meio } \\
\text { do reconhecimento do papel do patrimônio cultural e da } \\
\text { educação na redução do risco de desastres. }\end{array}$ \\
\hline $\begin{array}{l}\text { 8. Aumentar a resiliência de } \\
\text { infraestruturas }\end{array}$ & $\begin{array}{c}\text { Avaliar a capacidade e a adequação dos sistemas de } \\
\text { infraestrutura crítica, bem como os seus vínculos entre } \\
\text { eles, e atualizá-los de acordo com os riscos identificados na } \\
\text { dimensão } 2 \text {. }\end{array}$ \\
\hline $\begin{array}{l}\text { 9. Assegurar a resposta efetiva de } \\
\text { desastres }\end{array}$ & $\begin{array}{c}\text { Com base nos cenários da dimensão 2, assegurar uma } \\
\text { resposta efetiva ao desastre. }\end{array}$ \\
\hline $\begin{array}{l}\text { 10. Assegurar a rápida recuperação e } \\
\text { a melhorias com a reconstrução }\end{array}$ & $\begin{array}{l}\text { Assegurar planos pré-desastre suficientes de acordo com } \\
\text { os riscos identificados, e que após qualquer desastre, as } \\
\text { necessidades dos afetados estejam no centro de } \\
\text { recuperação e reconstrução, com seu apoio para projetar } \\
\text { e implementar a reconstrução. }\end{array}$ \\
\hline
\end{tabular}

Fonte: UNISDR, 2017.

O Indicador de Preparação a Desastres para Cidades (IPDC) foi desenvolvido pelo curso de mestrado em Gestão Urbana da Pontifícia Universidade Católica do Paraná (PUCPR) em conjunto com o Centro Universitário de Estudos e Pesquisas sobre Desastres (CEPED/PR), sendo resultado de um projeto de pesquisa financiado pela Companhia de Saneamento do Paraná (Sanepar). O presente instrumento é constituido de onze dimensões e subdividido em 46 subitens (Tabela 2). 
Tabela 2. Dimensões do IPDC

\section{Dimensões do IPDC}

Desenvolvimento Institucional

Desenvolvimento de Recursos Humanos

Mudança Cultural

Desenvolvimento Científico e Tecnológico

Motivação e Articulação Empresarial

Informações e Estudos Epidemiológicos sobre Desastres

Monitorização, Alerta e Alarme

Planejamento em redução do risco de desastre, proteção e defesa civil e resiliência

Estratégias para a proteção de populações contra riscos focais

Mobilização

Aparelhamento e apoio logístico
Existência de órgão de coordenação

Equipe técnica exclusiva para coordenação

Decreto nomeação

Conselho Municipal GRD

Análise / Participação Legislativa

Participação Judiciário

Capacitação básica - coordenação

Capacitação GRD setorial

Treinamento continuado

Conexão com universidades

Integração com monitoramento

Sistema Alerta (coordenação)

Sistema Alarme População

Sistemas de Inteligência

SMS-moradores

Aplicativos

Campanhas

Divulgação do Risco

Ícones Culturais

Entidades participando do Conselho

PAM/NUDEC (Plano de Auxílio Mútuo e/ou

Núcleos de Proteção e Defesa Civil)

Conhecimento sobre valor/impacto danos e prejuízos

Histórico dos desastres

Áreas de atenção

Precisão e Domínio da Metodologia de Avaliação (dados)

Contato com Centro Estadual / Nacional

Disseminação da Informação

Controle de Qualidade

Existência de Alarme / Método

Plano Municipal PDC

Plano de Contingência

Revisões/Divulgação

Simulados

Exercício Evacuação

Programas Habitacionais

Alarme

Abrigos

Segurança

Grupos Setoriais

Voluntários

Órgãos Emergenciais

Donativos

Abrigos

Base de Apoio Logístico

Reserva Orçamentária

Cadastro dos Recursos

Fonte: PINHEIRO, GARCIAS e FERENTZ, 2017 ne.

O desenvolvimento do presente indicador teve como objetivo a criação de uma ferramenta de avaliação da preparação dos municípios frente aos riscos e à ocorrência de eventos extremos. Isto se deu a partir da problemática de que ainda 
hoje muitos gestores locais não possuem capacitação adequada, fazendo com que os impactos negativos no meio urbano e nos serviços ecossistêmicos sejam amplificados (DALMAU, MACHADO e FRANCO, 2015). As ameaças provenientes de eventos naturais ou tecnológicos sempre irão existir, mas se a gestão de riscos municipal for eficiente, os impactos serão minimizados ou até eliminados por completo (ONU, 2010).

Buscando pelo equilíbrio da importância das dimensões do indicador de preparação, foi definido que cada uma delas se constituissem do mesmo peso total final. Deste modo, cada dimensão foi subdividida em parcelas igual para se obter o peso 1 ao final, independentemente da quantidade de questões que cada uma delas é formada (PINHEIRO, GARCIAS e FERENTZ, 2017 ne).

Além disto, destaca-se que tanto o Scorecard quanto o IPDC apresentam seus resultados por meio da metodologia do gráfico Radar, a fim de analisar as diferentes dimensões e variáveis ao mesmo tempo. Estes gráficos circulares possuem representação de diversos eixos radiais, sendo que "as intersecções entre os raios e a circunferência representam os valores máximos que as variáveis representadas nos mesmos podem alcançar" (UNED, 2003, p. 37). A adaptação realizada para o Indicador de Preparação é chamada de Círculo Pleno, tendo o objetivo de uma análise visual rápida dos resultados (PINHEIRO, GARCIAS e FERENTZ, 2017 ne).

Anteriormente a aplicação dos indicadores, foi necessário determinar a amostra de pesquisa. Conforme os dados do CRED (2017), milhões de pessoas foam atingidas por desastres naturais no mundo entre os anos de 2006 a 2016, sendo as maiores ocorrências registradas referentes aos desastres hidrológicos (51,5\%), com os maiores impactos sendo resultantes das inundações. Em observância ao Sistema de Defesa Civil do Paraná (SISDC), dentre as ocorrências do estado, constatou-se que o município paranaense com os maiores registros de inundação se refere a União da Vitória.

O município de União da Vitória está localizado ao sudeste do estado, sendo considerado uma represa natural, devido as características da formação rochosa do rio Iguaçu. Além disto, a pouca declividade do rio por todo o trecho de União até Porto Vitória é outro fator que contribui para a formação das áreas alagadiças da região (SEC-CORPRERI, 1999).

O município possui registros em livros históricos sobre grandes enchentes em 1891, 1905, 1911 (SILVA, 1933), 1935, 1957 e 1970 (FRANÇA, 1983). Segundo o Relatório de Ocorrências da Defesa Civil do Paraná, os desastres de União da Vitória iniciaram seu registro eletrônico em 1980, apresentando ocorrências até 2017, totalizando em 60 incidentes com 112.479 pessoas afetadas. Das 60 ocorrências, 31 estão relacionadas às inundações, as quais resultaram em 7 óbitos (SISDC, 2018).

Os gestores de proteção e defesa civil de União da Vitória, precisam estar diretamente conectados aos demais setores do município, pois na ocorrência de desastres, todos os serviços ofertados possuem algum tipo de restrição. Uma maneira de lidar com a prevenção de grandes impactos é o monitoraramento diário dos níveis do rio Iguaçu realizados também, em conjunto com os outros municípios a montate de União da Vitória. Esta necessidade se faz presente devido o histórico de impactos negativos que as grandes inundações de 1983, 1992 e 2014 deixaram na cidade e em seus moradores. 
Deste modo, os presentes indicadores foram aplicados em conjunto com o coordenador municipal de proteção e defesa civil e com os gestores das áreas setoriais, a fim de se obter as informações indispensáveis em todos os aspectos essenciais (saúde, educação, infraestrutura, meio ambiente, etc.). Para esta aplicação, foram necessárias algumas reuniões na cidade de União da Vitória, as quais foram realizadas em pequenos grupos de um ou dois setores e também na forma de entrevistas individuais, com a leitura dos instrumentos de pesquisa e sua respectiva coleta de dados pelos respondentes. Esta coleta se deu nos meses de abril e junho de 2018, resultando nas informações apresentadas a seguir.

\section{Resultados e Discussões}

Para a análise da Gestão de Riscos e Desastres (GRD) de União da Vitória, foi realizada a sudvisão dos 164 indicadores (118 do scorecard e 46 do IPDC) nas fases da gestão de riscos (prevenção, mitigação e preparação) e nas da gestão de desastres (resposta e recuperação), a fim de se identificar os elementos que influenciam as ações dos coordenadores municipais em cada uma destas etapas. Esta reestruturação dos instrumentos de pesquisa resultou na subdivisão dos itens em $84,8 \%$ para análise de gestão de risco e em 15,2\% para a análise da gestão de desastres.

Destaca-se que, embora a gestão de riscos tenha resultado em um percentual maior para análise do que a gestão de desastres, isto não minimiza a importância das etapas de resposta e recuperação. Embora elas sejam mais difíceis de medição, são as que ainda recebem os maiores recursos financeiros nos municípios quando se trata de desastres.

$\mathrm{Na}$ análise da gestão de riscos, a etapa de prevenção apresentou como principal ponto positivo a utilização de um mapa de risco, ou mapa de cotas como é chamado pelos gestores municipais, para a tomada de decisões relacionadas a construção de novos empreendimentos. As cotas não só estão presentes no escopo do Plano Diretor de União da Vitória como também serviram de base para a elaboração dos mapeamentos das grandes inundações que ocorreram no município desde 1983. Além disto, o mapa de cotas auxilia os gestores quanto a permissividade de construções e quanto ao angariamento de financiamentos, já que a caixa econômica federal não libera recursos financeiros para áreas que estejam dentro das cotas de inundação.

Por outro lado, como pontos negativos da presente etapa pode-se citar a falta de integração setorial, a qual poderia ser resolvida com a criação de um comitê de resiliência; a falta de integração intermunicipal, tendo em vista que União da Vitória e Porto União são separadas apenas pelos trilhos ferroviários; e a inexistência de dados quantitativos precisos sobre quantidade a de pessoas, empregos, comércios e áreas agrícolas com maiores riscos na ocorrência de desastres.

$\mathrm{Na}$ etapa de mitigação destaca-se dois pontos positivos, sendo o primeiro a quantidade de estudos técnicos que visam soluções para a minimização dos impactos negativos das inundações. Dentre estes projetos, um dos melhores é considerado o Parque Ambiental, o qual envolveu a realocação de centenas de pessoas que viviam às margens do Rio Iguaçu e hoje funcionada como uma medida de mitigação com a contenção de cheias. O segundo ponto positivo se refere a constante busca que os representantes locais realizam para angariar investimentos estaduais ou federais, a 
fim de construir novas moradias para a realocação de mais pessoas quem estejam em área de risco.

Embora estas questões sejam positivas, cabe apresentar alguns pontos negativos encontrados: existência de infraestruturas essenciais em áreas de risco, como escolas e a principal estação de tratamento de esgoto; não há previsão para realocação ou implantação de medidas construtivas em determinados bairros da cidade, o que causa a impressão que estas áreas são permissíveis para construções agravando a situação; e por mais que novas residências sejam construídas para pessoas que vivem em áreas de risco, não são considerados padrões construtivos que auxiliem na minimização de impactos ao meio ambiente, como a utilização de infraestruturas verdes e azuis.

A etapa de preparação apresentou como ponto positivo a dedicação e acompanhamento constante dos gestores quanto aos níveis do rio Iguaçu para que, se necessário, as medidas sejam tomadas o mais rápido possível. Também foi observado que mesmo com a grande frequência de inundações, os dados municipais não são perdidos, assim como os serviços não são completamente interrompidos, apenas de maneira parcial em grandes inundações. Por fim, a forte cultura local de organização e voluntariado para ajudar as pessoas afetadas é o último ponto positivo a ser destacado na presente etapa.

Em relação aos principais pontos negativos, ficou claro que a população conhece os riscos locais e as cotas que atingirão suas casas, no entanto, não são realizados quaisquer tipos de treinamento ou capacitações com as pessoas das comunidades ou com os alunos das escolas do município, sendo este o principal ponto negativo apontado pela pesquisa. Além disto, cabe também apontar que ainda não existe um canal de comunicação específico para a gestão de riscos e desastres com a comunidade, sendo utilizada a página da prefeitura no site ou facebook para divulgações esporádicas, assim como não existe um núcleo comunitário específico para os assuntos dos riscos locais, apenas associações de moradores.

Em relação à análise da gestão de desastres, a etapa de resposta tem como pontos positivos a participação intensa de militares, exército e voluntários para o atendimento rápido das pessoas afetadas. Desta forma, a organização local em relação a preparação de abrigos e recursos é realizada antes mesmo dos desastres atingirem seu estado crítico. No entanto, cabe ressaltar que no Plano de Contingência municipal, os abrigos cadastrados não são suficientes para atendimento em grandes inundações, sendo necessária a utilização de outros locais complementares. Além disso, a cidade também não possui nenhum tipo de alarme sonoro para inundações repentinas, como a que ocorreu em 1983 durante a noite, sendo utilizado, principalmente, as redes sociais e o rádio para o aviso da população.

Na fase final, de recuperação, tem-se como principal ponto positivo a participação de toda a comunidade, assim como dos demais municípios do estado, de tal forma que muitas doações são recebidas para ajudar as famílias no enfrentamento do pósdesastre. No entanto, foi possível observar que não é realizado nenhum tipo de planejamento de recuperação ou de reativação econômica, o que dificulta a preparação das pessoas para a ocorrência de próximos eventos. Com a coleta de informações, principalmente de auto avaliações que demonstrem o que se fez de errado e o que pode ser melhorado, é possível traçar novas metas e objetivos para se tornar mais resiliente. 
Além das análises qualitativas das etapas da gestão de riscos e desastres, cabe destacar os resultados quantitativos apresentados. Com a aplicação dos instrumentos de pesquisa, a pontuação encontrada foi de 52,4\% para prevenção, 49,6\% para mitigação, 39,8\% para preparação, 85,4\% para resposta e 13,3\% para recuperação. O total geral obtido pela gestão municipal de União da Vitória foi de 52,5\% de resiliência aos desastres de inundação.

Em relação aos resultados individuais dos instrumentos utilizados para a presente pesquisa, buscou-se desenvolver um estudo comparativo entre municípios, afim de análisar o método utilizado de forma aprofundada. Deste modo, além de União da Vitória, adotou-se a cidade de Campo Largo para a avaliação dos indicadores. Com a aplicação do Indicador de Preparação, o município de União da Vitória atingiu uma pontuação total de 46,3\%, enquanto que Campo Largo apresentou 71,3\% (Tabela 3).

Tabela 3. Resultados do IPDC de União da Vitória e Campo Largo

\begin{tabular}{|c|c|c|}
\hline Dimensões do IPDC & $\begin{array}{c}\text { União da } \\
\text { Vitória }\end{array}$ & $\begin{array}{c}\text { Campo } \\
\text { Largo }\end{array}$ \\
\hline Desenvolvimento Institucional & 0,33 & 0,67 \\
\hline Desenvolvimento de Recursos Humanos & 0,33 & 0,33 \\
\hline Desenvolvimento Científico e Tecnológico & 0,14 & 0,86 \\
Mudança Cultural & 0,33 & 0,67 \\
\hline Motivação e Articulação Empresarial & 0,00 & 0,67 \\
\hline Informações e Estudos Epidemiológicos sobre Desastres & 1,00 & 1,00 \\
\hline Monitorização, Alerta e Alarme & 0,25 & 0,50 \\
\hline Planejamento Operacional e de Contingência & 0,50 & 0,75 \\
\hline Aparelhamento e apoio logístico & 0,60 & 0,60 \\
\hline TOTAL & 1,00 & 1,00 \\
\hline
\end{tabular}

Fonte: FERENTZ, 2018.

É possível observar que dentre as onze dimensões analisadas, apenas duas apresentaram a pontuação máxima nos municípios de análise, sendo as Informações e Estudos Epidemiológicos sobre Desastres, que trata do histórico de desastres e demais informações relacionadas às áreas de atenção, assim como a Mobilização, que trata das ações de voluntários e demais órgãos. Além disto, outros dois itens que apresentaram uma pontuação acima da média em ambos foram nas dimensões de Estratégias para a proteção de populações contra riscos focais e de Aparelhamento e apoio logístico.

Em contrapartida, embora Campo Largo tenha apresentado resultados acima da média em outras cinco dimensões, União da Vitória não só obteve notas menores como também teve uma de suas dimensões zeradas: Motivação e Articulação Empresarial. Conforme identificado durante as análises qualitativas, a integração com as áreas setoriais e municípios vizinhos não só é inexistente, como também falta a realização de parcerias como setor privado. A partir dos resultados obtidos pelo IPDC, é possível afirmar que a base estrutural da gestão é mais forte no município de Campo Largo do que em União da Vitória, mesmo que o primeiro não apresente um histórico frequente de desastres (Gráfico 1).

\section{Gráfico 1. Resultados do IPDC de União da Vitória e Campo Largo}


IPDC - UNIÃO DA VITÓRIA

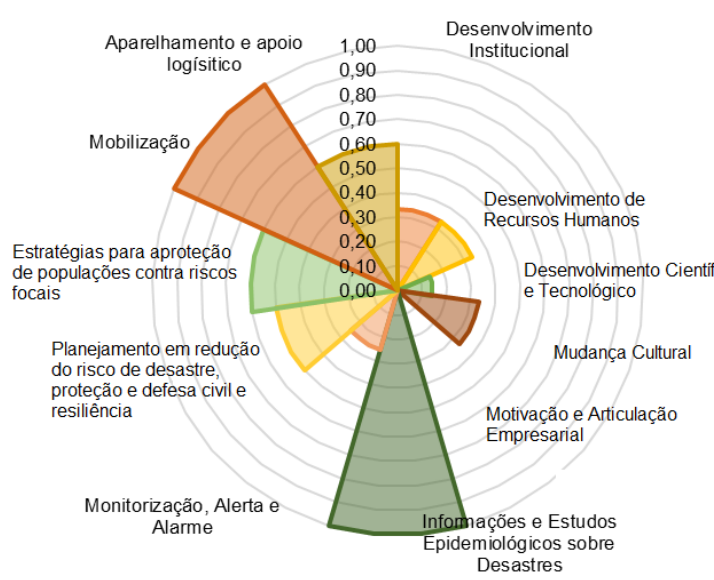

Fonte: FERENTZ, 2018.

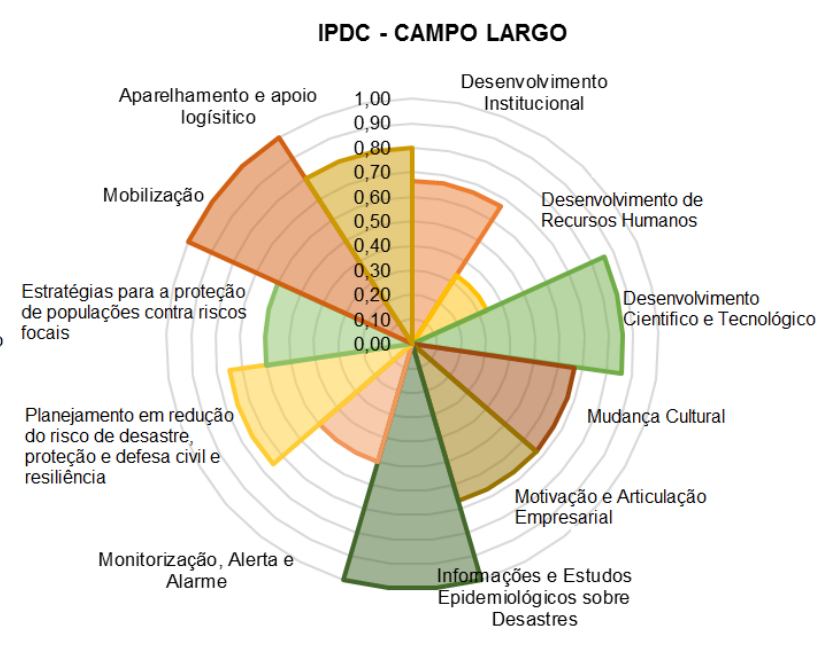

Contudo, enquanto que na análise do IPDC Campo Largo se mostrou mais preparado do que União da Vitória, na aplicação do Scorecard para Cidades Resilientes os resultados foram o oposto. União da Vitória apesentou um total de 53,2\% e Campo Largo 24,2\% (Tabela 4).

Tabela 4 - Resultados do Scorecard de União da Vitória e Campo Largo

\begin{tabular}{|c|c|c|}
\hline Passos para a Resiliência & $\begin{array}{c}\text { União da } \\
\text { Vitória }\end{array}$ & Campo Largo \\
\hline $\begin{array}{c}\text { 1. Organizar a resiliência de desastres } \\
\text { futuros }\end{array}$ & $57,8 \%$ & $20,0 \%$ \\
\hline 3. Fortalecer a capacidade financeira para resiliência & $63,3 \%$ & $16,7 \%$ \\
\hline 4. Buscar pelo desenvolvimento urbano resiliente & $32,0 \%$ & $22,0 \%$ \\
\hline 5. Proteger os sistemas naturais para melhorar as funções de & $42,0 \%$ & $0,0 \%$ \\
proteção oferecidas pelos ecossistemas & $33,3 \%$ & $46,7 \%$ \\
\hline 6. Fortalecer a capacidade institucional para resiliência & $41,5 \%$ & $7,7 \%$ \\
\hline 7. Encontrar e fortalecer a capacidade social para resiliência & $66,0 \%$ & $14,0 \%$ \\
\hline 9. Aumentar a resiliência de infraestruturas & $55,8 \%$ & $46,1 \%$ \\
\hline 10. Assegurar a resposta efetiva de desastres & $76,5 \%$ & $16,5 \%$ \\
\hline
\end{tabular}

Fonte: FERENTZ, 2018.

Ao contrário do que foi apresentado no Indicador de Preparação, nenhuma das dimensões do Scorecard alcançou pontuação máxima ou pontuação similar nos dois municípios de estudo. Além disto, cabe destacar que Campo Largo não apresentou nenhum resultado acima da média, assim como ainda teve uma de suas dimensões zeradas: buscar pelo desenvolvimento urbano resiliente. $O$ único passo em que Campo Largo atingiu uma pontuação maior que União da Vitória foi o de número 5 , proteger os sistemas naturais para melhorar as funções de proteção oferecidas pelos ecossistemas.

Diferentemente do IPDC, os resultados do Scorecard Detalhado apresentam a avaliação da atuação municipal frente a sua resiliência à ocorrência de eventos 
extremos, a fim de se identificar as forças e fraquezas da gestão. Sendo assim, União da Vitória obteve uma pontuação muito mais significativa quanto a atuação da Proteção e Defesa Civil e de seus grupos setoriais (Gráfico 2). Ressalta-se novamente que Campo Largo não possui a mesma frequência de desastres que União da Vitória, por isto a atuação do segundo município se faz muito mais estruturada já que ele precisa lidar com as inundações de forma constante.

A partir da análise individual dos instrumentos de pesquisa, foi possível observar a necessecidade de estudos aprofundados em relação aos presentes indicadores, tendo em vista a convergência dos resultados apresentados tanto para União da Vitória quanto para Campo Largo. Muito além da metodologia estrutural de cada um, é importante verificar se as dimensões e itens analisados condizem com a realidade dos municípios, a fim de se utilizar instrumentos que caracterizem, de fato, a gestão de riscos de desastre local. Não obstante, cabe destacar que a resiliência vai além da aplicação de indicadores, sendo necessária a união de forças para a elaboração do Plano Municipal para a Resiliência, assim como para seu monitoramento posterior e contínuo atingimento de metas.

\section{Gráfico 2. Resultados do Scorecard de União da Vitória e Campo Largo}
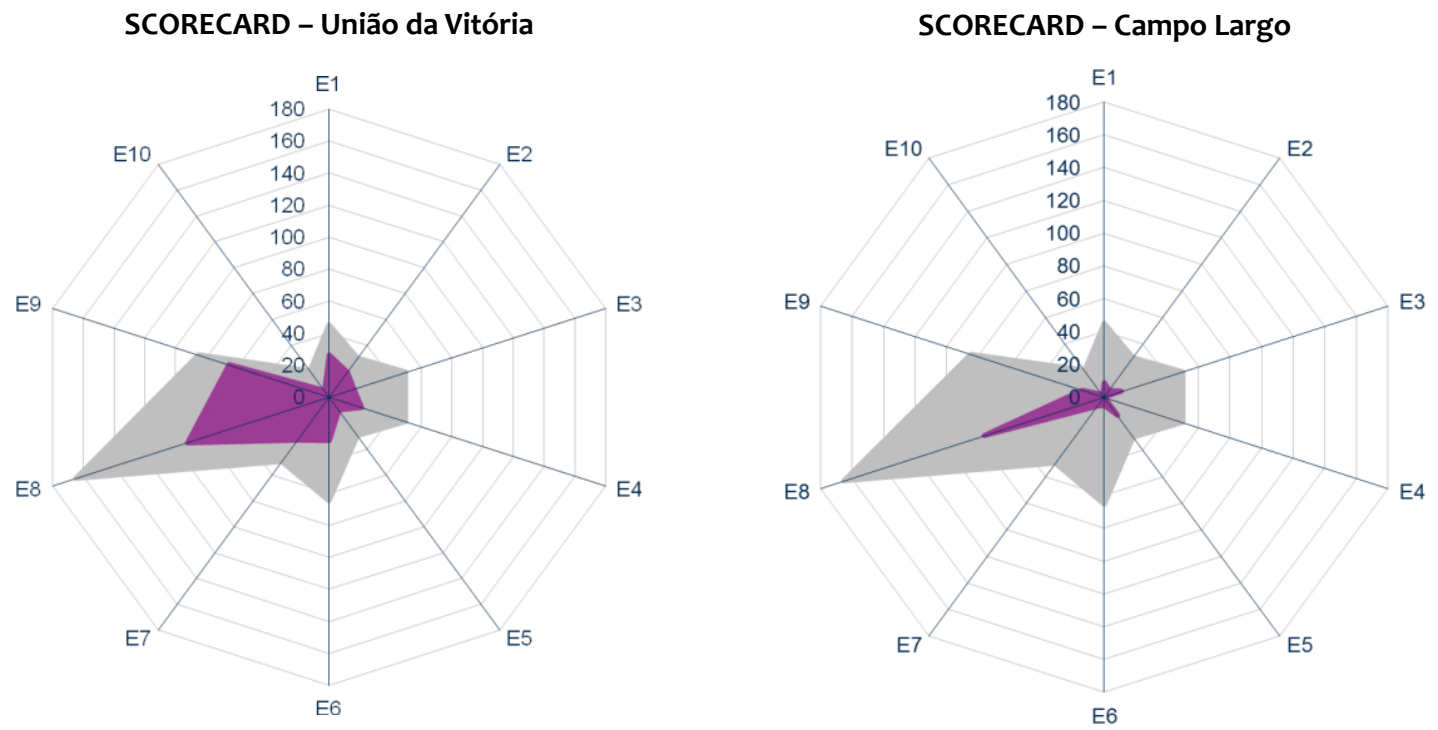

Fonte: FERENTZ, 2018

Esta análise comparativa não só foi importante para avaliar os próprios instrumentos utilizados, mas também para verificar os principais padrões e contradições entre os municípios em estudo. A principal contradição encontrada se refere a integração setorial, de tal forma que Campo Largo possui um comitê de resiliência formado, facilitando as reuniões e preenchimento das ferramentas, enquanto que em União da Vitória foi necessária a visita em cada uma das secretarias para cumprimento do objetivo.

Em relação aos padrões, foi observado em ambos os municípios a inexistência de planos financeiros para a redução de riscos de desastres; a inexistência de parcerias entre os setores público e privado; a inexistência de planos que visem o reconhecimento dos impactos em cadeia sofridos a cada desastre; e por fim, a inexistência de capacitação perante as comunidades quanto os riscos a serem enfrentados e a importância das ações prévias de cada um frente aos desastres. 
Sobre esta última problemática, é importante que a gestão municipal realize a incorporação da perspectiva das pessoas nas ações de minimização dos riscos e impactos dos desastres. Isto se faz necessário por dois motivos principais: primeiro que não é possível tornar o município resiliente se os moradores não considerarem a resiliência em suas atividades diárias e segundo, que ninguém é mais capaz de indetificar os pontos críticos de cada área em risco do que os próprios residentes, os quais tem de convier com eles.

Em primeiro momento, entende-se que é necessário trabalhar com a mudança da mentalidade dos moradores, estabelecendo uma nova cultural local. Atualmente ainda é visível a resistência que as pessoas possuem para sair de suas casas e irem viver em outro lugar, mesmo que este outro seja mais seguro. Além disto, também foi identificada a chamada "indústria das cheias", onde algumas famílias se mudam temporariamente para áreas de risco a fim de receber benefícios do governo.

Estes fatores são influenciados pelo apego das comunidades quanto sua cultura e sua história nestes locais. No entanto, é muito difícil para os gestores terem de aceitar que estas pessoas estão acostumadas a conviver com as cheias do Iguaçu, de tal modo que a perda de bens e dos danos causados nas infraesturas dos bairros e de suas próprias casas se tornou algo comum para elas. O abandono destas comunidades por justificativas que são adotadas ao longo dos anos só causa o retardo do progresso do município, assim como continua colocando cada vez mais pessoas em risco.

Além dos aspectos sociais e culturais, outro fator identificado para a inclusão nas medidas de gestão de riscos de desastre, é o apoio psicológico contínuo às famílias afetadas pelas inundações. Este ponto é muito importante tendo em vista que os problemas psicológicos podem começar a ocorrer até mesmo muitos anos após o contato com o evento crítico, além de que questões como desemprego, estresse e depressão não são considerados no processo de recuperação dos municípios. No caso de União da Vitória, embora haja épocas sem grandes registros de cheias, o que causa uma conformidade pelas perdas e até mesmo um comodismo da população, quando uma nova enchente ocorre, os problemas de revolta social voltam a ocorrer.

Por isto, é imprescindível que os representantes locais analisem todos os parâmetros de interrelação entre comunidade e gestão, a fim de incluir estes fatores nos processos de decisão. Estas dimensões sociais devem ser consideradas como uma complementação aos instrumentos já utilizados, e não serem tratadas como questões unilaterais, tendo em vista que para se alcançar o objetivo da resiliência é necessário que todos trabalhem em conjunto.

Com o estabelecimento de uma relação integrada entre os gestores e as comunidades será possível a implantação de novas atividades no município, levando em conta o cumprimento dos deveres de cada cidadão. Por exemplo, novas obras realizadas para a redução dos riscos terão o zêlo da comunidade para que a eficiência das infraestruturas reflita de maneira positiva quando eventos extremos ocorrerem. Em contrapartida, a gestão também deverá se manter aberta para ouvir as pessoas, com suas críticas e sugestões, fechando um ciclo complementar para alcançar a máxima resiliência.

Tomando estas dimensões sociais como referência, em conjunto com os demais aspectos identificados nas análises quali-quantitativas, foi possível elaborar 
um mapa de sugestões em relação às medias de realocação de moradores e adaptação dos serviços e infraestruturas de União da Vitória (Figura 3). Com base na legislação federal e nos planos municipais, adotou-se a complementação do Parque Ambiental por toda a extensão do município como uma primeira medida, tendo em vista que se respeitadas, as áreas de preservação permanente devem cumprir 200 metros de cobertura vegetal a partir do leito do rio Iguaçu.

Para isto, é importante que a população que vive nestas áreas seja comunicada sobre os riscos existentes em habitar estes locais e sobre a possibilidade de realocação, tendo o acompanhamento social e psicológico desde o primeiro contato. Para definição das famílias prioritárias, análises técnicas de infraestrutura devem ser realizadas nas residências, a fim de averiguar se existe o risco de desabamento. Com o início das mudanças, não só foi considerado a atual prospecção imobiliária do município em áreas distantes dos riscos de inundação, como também foi sugerida a verticalização central, a fim de realocar moradores na própria área urbana consolidada.

Por fim, foi considerada a principal problemática de União da Vitória, quanto a falta de capacitação das comunidades, para a última sugestão estrutural: a construção de um Observatório para o resgate da memória das inundações do município. De um lado tem-se a relação do município com sua própria comunidade, onde é necessário implementar medidas que auxiliem na mudança da cultura local e da conscientização quanto aos riscos das inundações. Do outro lado, União da Vitória é vista como exemplo para outros municípios da região, devido a efetividade de suas ações quanto a resposta a desastres.

\section{Figura 3. Mapa das Medidas de Realocação e Adaptação de União da Vitória}

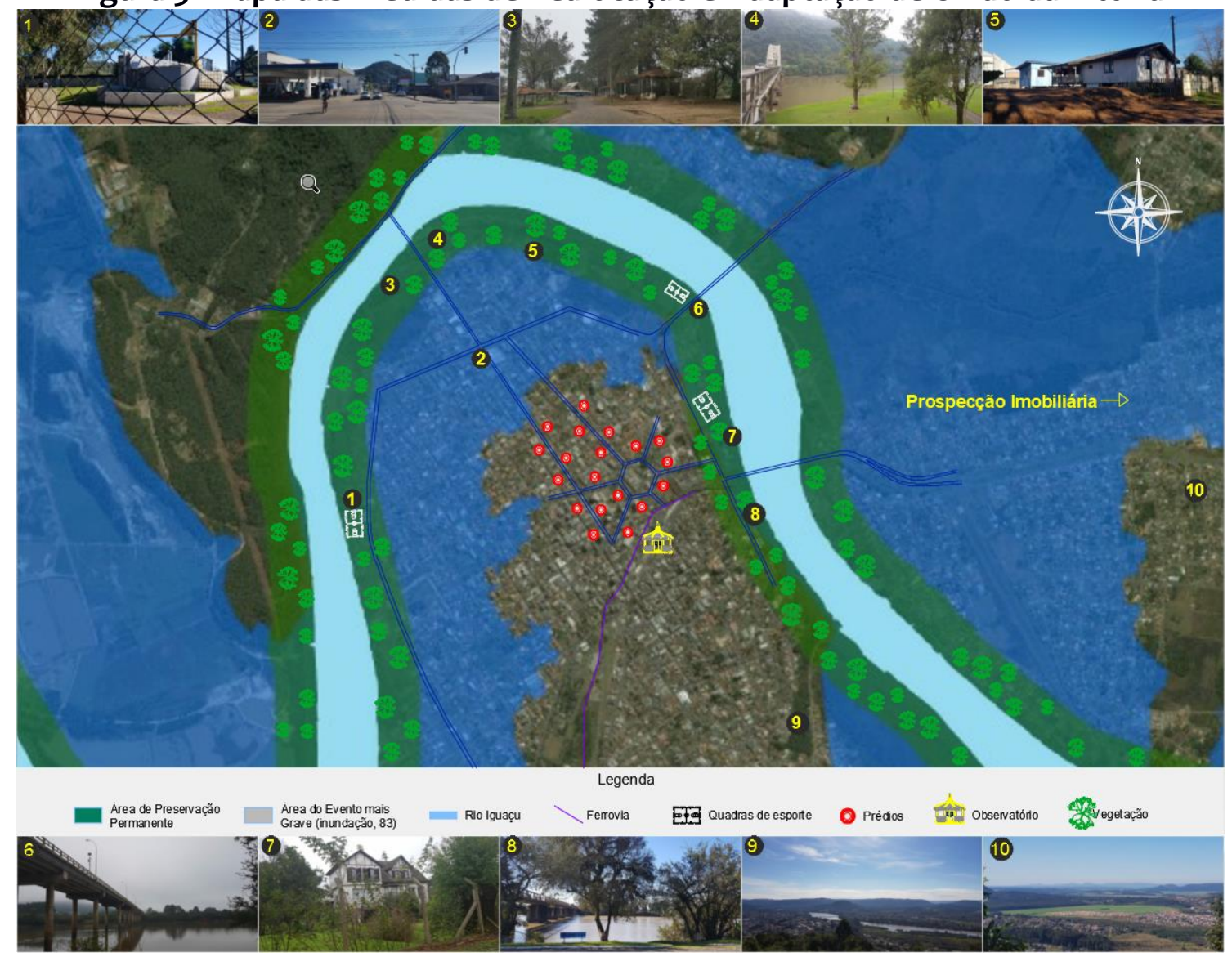


Fonte: FERENTZ, 2018.

Por isto, a criação de um elemento cultural, o qual se fará de referência para toda a região, auxiliará os representantes locais na identidade da resiliência do município, tendo em vista que este empreendimento será lembrado como um centro de gestão de riscos e desastres. Para a construção do Obsevatório, identificou-se um dos principais monumentos históricos de União da Vitória: a antiga Estação Ferroviária (Figura 4), a qual já representa a história dos moradores locais durante o maior desastre de inundação do município.

A oportunidade desta construção representa o resgate das memórias de União da Vitória, com a doação de documentoes, fotografias e relatos dos próprios moradores. Não obstante, ela também permitirá a capacitação da população em relação a sua própria história, de tal forma que as pessoas terão a oportunidade de conhecer todos os avanços conquistados após cada inundação. 
Figura 3. Mapa das Medidas de Realocação e Adaptação de União da Vitória

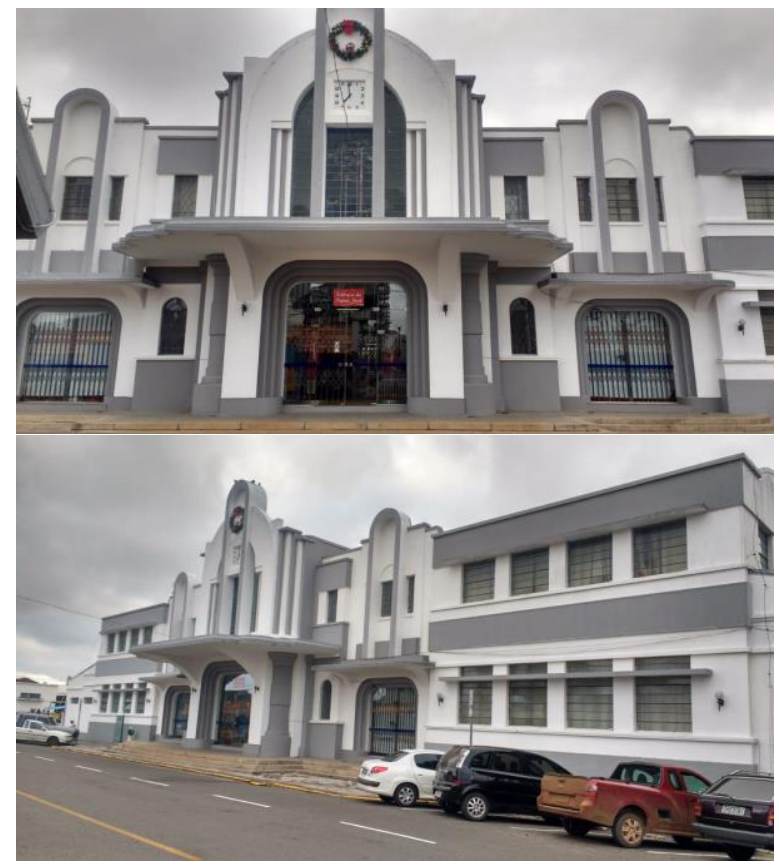

Fonte: os autores.

Com uma infraestrutura física, que se transforme no marco cultural do enfrentamento das inundações, o espaço poderá ser utilizado também como polo central de atividades escolares, projetos de pesquisa e relação direta com universidades. Além disto, as capacitações e visitações não devem ficar restritas aos moradores, mas também se transformar em uma oportunidade de divulgação de conhecimento para outros municípios, a fim de compartilhar as experiências vividas para ajudar as outras comunidades.

Neste sentido, reforça-se que a coordenação de proteção e defesa civil, assim como de sua equipe, deva ter um cargo exclusivo para ações que visem a redução de riscos e desastres, pois são estes os profissionais que poderão manter a essência do Observatório viva. As funções destes gestores vão muito além do atendimento na ocorrência de desastres, sendo primordial sua atuação em atividades prévias a eventos extremos.

A capacitação da população é umas das questões mais essenciais e necessárias para a resiliência. São as pessoas que constroem as cidades, com trabalho, cultura e relações. Quanto mais tempo a gestão local levar para reconhecer a importância social e realizar investimentos que fortifiquem estes laços, mais difícil será de alcançar os objetivos e conquistar um município mais resiliente.

\section{Conclusão}

A inclusão da perspectiva social na gestão de riscos e desastres dos municípios é essencial para a efetividade dos processos, tendo em vista que se os investimentos e ações forem tomadas apenas do lado institucional, o patamar esperado pode não ser atingido, já que a atuação das comunidades não é considerada nestes processos. Por isto, a sensibilização da população de União da Vitória foi a maior falha identificada na aplicação dos instrumentos de pesquisa. 
Deste modo, a construção de um Observatório surge como uma nova proposta para o resgate cultural de relações entre os níveis da sociedade. Ele também foge do padrão de capacitação local, onde as atividades são restritas a determinados grupos de participantes, sejam nas escolas ou associações de moradores. Ele é um processo de mudança contínua, com a construção de uma nova identidade, a qual permite o compartilhamento de informações além das divisas de União da Vitória.

Quando o conhecimento é repassado, novos pensamentos começam a surgir, sendo uma oportunidade para a construção de outras propostas e soluções. Além disto, inicia-se a fortificação da cultura de gestão de riscos por meio da integação entre os diferentes atores da sociedade, não focando apenas em quando os desastres já ocorreram. É por isto que a integração pode ser considerada como a primeira medida a ser solucionada para que as cidades se tornem mais resilientes.

\section{REFERÊNCIAS}

ALDRICH, D. P. Alcançando resiliência: Resiliência 2.0 do manual para profissionais de ajuda e formuladores de políticas. Observatório da Cidade Resiliente, 2017. Disponível em: <https://theconversation.com/recovering-from-disasters-socialnetworks-matter-more-than-bottled-water-and-batteries-69611>. Acesso em: 28 nov. 2017.

BAUMEL, L. F. S., et al. Brigada Escolar - Defesa Civil na Escola. Curitiba: Escola de Defesa Civil do Paraná, 2013.

BRASIL. Drecreto n ${ }^{\circ} \mathbf{9 . 5 5 7}$ de 6 de dezembro de 2013. Institui o Regulamento do Sistema Estadual de Proteção e Defesa Civil - SEPDEC, o Centro de Estudos e Pesquisas sobre Desastres - CEPED e dá outras providências. Curitiba, em 06 de dezembro de $2013,192^{\circ}$ da Independência e $125^{\circ}$ da República.

BRASIL. Lei $\mathbf{n}^{\circ}$ 9.943 de 27 de abril de 1992. Dá nova redação ao art. 17, da Lei $n^{\circ}$ 8.485, de 03 de junho de 1987 (âmbito de ação da casa Militar). Palácio do Governo em Curitiba, em 27 de abril de 1992.

BRASIL. Lei n 12.608 de 10 de abril de 2012. Institui a Política Nacional de Proteção e Defesa Civil - PNPDEC; dispõe sobre o Sistema Nacional de Proteção e Defesa Civil SINPDEC e o Conselho Nacional de Proteção e Defesa Civil - CONPDEC; autoriza a criação de sistema de informações e monitoramento de desastres; altera as Leis nos 12.340, de 10 de dezembro de 2010, 10.257, de 10 de julho de 2001, 6.766, de 19 de dezembro de 1979, 8.239, de 4 de outubro de 1991, e 9.394, de 20 de dezembro de 1996; e dá outras providências. Brasília, 10 de abril de 2012.

BRUNDTLAND, G. H., et al. Report of the World Commission on Environment and Development: Our Common Future. Oslo: United Nations, 1987. 187p. 
CEPED UFSC. Centro Universitário de Estudos e Pesquisa em Engenharia e Defesa Civil. Atlas Brasileiro de Desastres Naturais 1991 a 2010: volume Paraná. Florianópolis: CEPED UFSC, 2012. 77p.

CHRISTENSEN, E. V.; LEWIS, D.; ARMESTO, M. F. (org.) Guía de Resiliencia Urbana 2016. MEXICO. EUM. SEGOB. SEDATU. SNPC. Naciones Unidas, 2016. 57 p.

CRED. Centre for Research on the Epidemiology of Disasters. Annual Disaster Statistical Review 2016: The numbers and trends. Belgium: CRED. IRSS. Université catholique de Louvain, 2017. 91 p.

DALMAU, M. B. L.; MACHADO, M. A.; FRANCO, A. C. V. A Campanha Cidades Resilientes e o Plano Nacional de Gestão de Riscos e Desastres Naturais: avanços e perspectivas na construção de comunidades menos vulneráveis. Cadernos Adenauer. v. 16 n. 2, p. 95-113, 2015.

EIRD/ONU. Estrategia Internacional para la Reducción de Desastres de las Naciones Unidas. Marco de Acció de Hyogo 2005-2015. Aumento de la resiliencia de lãs naciones y las comunidades ante los desastres: Introducción al Marco de Acción de Hyogo. Genebra: EIRD, 2005.

FERENTZ, L. M. S. Gestão de Riscos e Desastres: a resiliência como instrumento de análise frente a ocorrência de eventos extremos. Dissertação (Mestrado em Gestão Urbana). Progama de Pós-Graduação em Gestão Urbana, PUCPR, Curitiba, 2018.

FOLKE, C., et al. Resilience and sustainable development: building adaptive capacity in a world of transformations. Ambio, v.31, n. 5, p. 437-440, 2002.

FRANÇA, V. de. Anatomia de uma Enchente. $2^{\text {a }}$ ed. COMDEC. SEED PR. Comissão de Alto Nível para Reconstrução. Grupo Executivo. União da Vitória: Editora Sulina Ltda, 1983.

FREITAS, C. M. de, et al. Desastres naturais e saúde: uma análise da situação do Brasil. Ciência \& Saúde Coletiva, v. 19, n. 9, p. 3645-3656, 2014.

MORENO, E. L.; OYEYINKA, O.; MBOUP, G. State of the World's Cities 2010/2011: Bridging The Urban Divide. 2 ed. London: United Nations Human Settlements Programme (UN-HABITAT), 2010. 244p.

ONU. Organização das Nações Unidas. Como Construir Cidades Mais Resilientes: Um Guia para Gestores Públicos Locais. Nações Unidas: Genebra, 2012. 102 p.

. Construindo Cidades Resilientes: Minha cidade está se preparando.

Tradução Sarah Marcela Chinchilla Cartagena. Florianópolis: Nações Unidas, 2010. 29 p. 
. Habitat III. Documentos Temáticos da Habitat III. n. 15. Resiliência

Urbana.Tradução de Barbara Rubin. ed. 2. Nova Iorque: Nações Unidas, 2015a. 10 p.

. Habitat III. Documentos Temáticos da Habitat III. n. 17. Cidades, Mudanças Climáticas e Gestão de Riscos de Desastres.Tradução de Barbara Rubin. ed. 2. Nova Iorque: Nações Unidas, 2015b. 12 p.

PINHEIRO, E. G. Orientações para o planejamento em Proteção e Defesa Civil: Plano Estadual de Proteção e Defesa Civil. Curitiba: FUNESPAR, 2017.

PINHEIRO, E. G.; GARCIAS, C. M.; FERENTZ, L. M. S. (org.). Indicador de Preparação para Desastres nas Cidades (IPDC). Curitiba: CEPED e PUCPR, 2017. No prelo.

PNRRC. Plataforma Nacional para a Redução do Risco de Catástrofes. Portugal: ISDR, 2017. Disponível em: <http://www.pnrrc.pt/>. Acesso em: 15 dez. 2017.

POTT, C. M. ESTRELA, C. C. Histórico ambiental: desastres ambientais e o despertar de um novo pensamento. Estudos Avançados: São Paulo, v. 31, n. 89, 2017.

SEC-CORPRERI. Sociedade de Estudos Contemporâneos - Comissão Regional Permanente de Prevenção contra Enchentes do Rio Iguaçu. Conhecendo e convivendo com as enchentes. União da Vitória - PR. Curitiba: SEMA/IAP, 1999.

SILVA, C. da. Apontamentos históricos de União da Vitória, 1768-1933. Coelção Adir Guimarães. $1^{\mathrm{a}}$ ed. (1000 exemplares). União da Vitória, 1933.

SISDC. Sistema de Defesa Civil do Paraná. União da Vitória - PR. Curitiba: Proteção e Defesa Civil, 2018.

SULAIMAN, S. N., ALEDO, A. Desastres naturais: convivência com o risco. Estudos Avançados: São Paulo, v. 30, n. 88, 2016.

TAVANTI, R. M., SPINK, M. J. Ações locais e prevenção: um estudo com adolescentes que vivem em áreas de risco socioambiental. Ambiente \& Sociedade: São Paulo, v. 17, n. 4, 2014.

UNED. Universidad Nacional de Educación a Distancia. Puntes de Diseño y Evaluacion de Configuraciones. Asignatura Optativa de 3 er Curso ( $2^{\circ}$ cuatrimestre) Ingeniería Técnica en Informática de Sistemas. Espanha: UNED, 2003.

UNISDR. United Nations Office for Disaster Risk Reduction. Disaster Resilience Scorecard for Cities: Detailed Level Assessment. United Nations, 2017. 118 p.

. Living with Risk: A global review of disaster reduction initiatives. v. 2 (Annexes). New York and Geneva, 2004. 
UNISDR.; CEPED PR. Estratégia Internacional das Nações Unidas para a Redução de Desastres. Centro de Estudos e Pesquisas sobre Desastres do Paraná.

Desenvolvimento de Capacidades para Tornar as Cidades mais Resilientes: Minha Cidade está se Preparando. Nações Unidas. Defesa Civil, 2010. 67p.

VESTENA, L. R. A importância da hidrologia na prevenção e mitigação de desastres naturais. Ambiência - Revista do Setor de Ciências Agrárias e Ambientais:

Guarapuava, v.4 n.1, 2007. 151-162 p.

Carlos Mello Garcias. Doutor em Engenharia Civil pela Universidade de São Paulo. Mestre em Recursos Hídricos e Saneamento Ambiental pela Universidade Federal do Rio Grande do Sul. Engenheiro Civil pela Universidade Federal do Paraná. carlos.garcias@pucpr.br

Larissa Ferentz. Doutoranda e Mestra em Gestão Urbana pela Pontifícia Universidade Católica do Paraná. Especialista em Gestão Ambiental pela Faculdade Futura e Engenheira Ambiental pela PUCPR. ferentzengenharia@gmail.com

Eduardo Gomes Pinheiro. Doutor e Mestre em Gestão Urbana pela Pontifícia Universidade Católica do Paraná. Bacharel em Segurança Pública - Curso de Formação de Oficiais pela Academia Policial Militar do Guatupê - APMG. Especialista em Emergências Ambientais, em Administração - Segurança Pública, em Metodologia do Ensino Superior e Educação à Distância, e em Redução do Risco de Desastre e Desenvolvimento Local Sustentável. egopinheiro@hotmail.com

Como citar: GARCIAS, Carlos Mello; FERENTZ, Larissa Maria da Silva; PINHEIRO, Eduardo Gomes. A Resiliência como Instrumento de Análise da Gestão Municipal de Riscos e Desastres. Redes, Santa Cruz do Sul, v. 24, n. 2, p. 99-121, maio 2019. ISSN 1982-6745. Disponível em: https://doi.org/10.17058/redes.v24i2.13241. 